\title{
Resposta de duas cultivares de arroz a doses de zinco aplicado como oxissulfato ${ }^{(1)}$
}

\begin{abstract}
Simone Cristina de Oliveira( ${ }^{(2)}$, Mirian Cristina Gomes $\operatorname{Costa}^{(3)}$, Raquel de Castro Salomão Chagas(2), Tatiele Anete Bergamo Fenilli(i), Reges Heinrichs ${ }^{(2)}$, Cleusa Pereira Cabral(2) e Eurípedes Malavolta( ${ }^{(4)}$

Resumo - O objetivo do trabalho foi avaliar o efeito de doses de $\mathrm{Zn}$, aplicado como oxissulfato, nas formas granulada e em pó, em duas cultivares de arroz. O experimento foi realizado em casa de vegetação em vasos com $3 \mathrm{dm}^{3}$ de um Latossolo Vermelho distrófico. Todos os vasos receberam calcário, macronutrientes e micronutrientes, com exceção do zinco. Foram aplicadas as doses de 0, 1, 2, 5 e $10 \mathrm{mg}$ de $\mathrm{Zn}$ por $\mathrm{dm}^{3}$ de solo. A dose de $4 \mathrm{mg} \mathrm{dm}^{-3} \mathrm{de} \mathrm{Zn}$ aplicado como sulfato foi usada como padrão de referência. $\mathrm{O}$ delineamento experimental utilizado foi o inteiramente casualizado com quatro repetições. O oxissulfato em pó na cultivar IAC 165 e granular na IAC 202 possibilitaram produções de grãos semelhantes às obtidas com o sulfato de zinco. Houve diferença nos teores de $\mathrm{Zn}$ nas folhas e colmos das duas cultivares associados à maior produção de grãos. A cultivar IAC 202 foi mais eficiente na utilização de Zn no crescimento vegetativo e na produção de grãos. Os teores de $\mathrm{Zn}$ extraídos por Mehlich 1 e DTPA correlacionaram-se significativamente com as doses de $\mathrm{Zn}$ aplicadas e com os níveis de $\mathrm{Zn}$ no tecido vegetal. Houve correlação significativa entre os dois extratores em relação às doses de $\mathrm{Zn}$ aplicadas no solo.
\end{abstract}

Termos para indexação: Oryza sativa, solo, micronutriente, extrato, solução.

\section{Response of two rice cultivars to rates of zinc applied as oxysulfate}

\begin{abstract}
The objective of this work was to evaluate the effect of doses of $\mathrm{Zn}$ oxysulfate in granular and powder forms on two rice cultivars in a Red Latosol (Hapludox). The trial was carried out in a greenhouse in pots with $3 \mathrm{dm}^{3}$ of soil. Lime, macronutrients and micronutrients except $\mathrm{Zn}$ were applied in all pots. Zinc rates were $0,1,2,5$ and $10 \mathrm{mg} \mathrm{dm}^{-3}$ of soil. Four $\mathrm{mg} \mathrm{Zn} \mathrm{dm}{ }^{-3}$ were used as a standard source of this nutrient. A completely randomized design with four replicates was used. Powder oxysulfate in the cultivar IAC 165 and the granular one in IAC 202 resulted grain yields similar to those obtained with $\mathrm{Zn}$ sulfate used as standard. There were differences in the $\mathrm{Zn}$ concentration in leaves and culms of the cultivars as associated to the higher grain production. IAC 202 was more efficient in the use of $\mathrm{Zn}$ for vegetative growth and grain yield. Available soil $\mathrm{Zn}$ extracted either by Mehlich 1 or DTPA showed significant correlation with the doses of $\mathrm{Zn}$ applied and with the $\mathrm{Zn}$ tissue content. There was significant correlation between $\mathrm{Zn}$ levels as evaluated by both extracting solutions.
\end{abstract}

Index terms: Oryza sativa, soil, micronutrients, extracts, solutions.

\section{Introdução}

As deficiências de B e Zn são as mais freqüentes nas culturas brasileiras (Malavolta et al., 1991). Te-

\footnotetext{
(1) Aceito para publicação em 12 de dezembro de 2002.

(2) Universidade de São Paulo (USP), Centro de Energia Nuclear na Agricultura (Cena), Caixa Postal 96, CEP 13400-970 Piracicaba, SP. E-mail: scolivei@cena.usp.br, rcschaga@cena.usp.br, tatiele@cena.usp.br, regesh@cena.usp.br, cpcabral@cena.usp.br

${ }^{(3)}$ Escola Superior de Agricultura Luiz de Queiroz (Esalq), Caixa Postal 9, CEP 13400-970 Piracicaba, SP.

(4)USP-Cena. Bolsista do CNPq. E-mail: mala@cena.usp.br
}

ores baixos de $\mathrm{Zn}$ no solo, calagem excessiva, baixos teores de matéria orgânica, temperaturas baixas, excesso de insolação, alto teor de P no solo ou na adubação, aplicações liberais de $\mathrm{N}$ e restrição para o desenvolvimento das raízes são causas da deficiência de Zn (Lucas \& Knezek, 1972). Além disso, existem diferenças genotípicas na absorção ou na utilização desse micronutriente por espécies e variedades (Brown et al., 1972), como demonstrado com arroz por Fageria (2001).

No período 1990/91, a área colhida com arroz no Brasil decresceu de 4.122.000 para 3.671.000 ha. A produção, entretanto, aumentou de 9.488 .000 para 
11.144.000 $\mathrm{t}$ graças ao aumento da produtividade, que passou de 2.302.000 para 3.036.000 $\mathrm{kg} \mathrm{ha}^{-1}$ (Associação Nacional para Difusão de Adubos, 2001). $\mathrm{O}$ uso de variedades melhoradas, práticas culturais adequadas e adubação na qual o Zn é incluído conforme as recomendações oficiais de adubação de arroz de sequeiro, de Minas Gerais (Ribeiro et al., 1999) e de São Paulo (Cantarella \& Furlani, 1996), têm contribuído para o incremento da produção.

Segundo Barbosa Filho et al. (1983), o teor crítico de $\mathrm{Zn}$ no solo para o arroz é de $0,9 \mathrm{mg} \mathrm{dm}^{-3}$ (Mehlich 1). Cantarella \& Furlani (1996) recomendam a adição de $Z n$ na adubação se o solo tiver entre 0,6 a $1,2 \mathrm{mg} \mathrm{dm}^{-3}$ de $\mathrm{Zn}$ extraído pelo DPTA. De acordo com Malavolta et al. (1997), o estado nutricional do arroz em relação aos diversos nutrientes é avaliado pela análise da folha Y (posição ocupada em relação à folha mais nova desenrolada imediatamente acima) amostrada no meio do perfilhamento, e o nível adequado situa-se entre 25 e $35 \mathrm{mg} \mathrm{kg}^{-1}$ de zinco. A folha bandeira coletada no início do florescimento deve ter entre 10 e $50 \mathrm{mg} \mathrm{kg}^{-1}$ de Zn (Cantarella \& Furlani, 1996).

Uma lista das fontes de Zn usadas no Brasil foi apresentada por Lopes (1999), em que algumas delas são solúveis em água. Podem ser aplicadas a lanço, no sulco de semeadura, nas folhas e nas sementes (Barbosa Filho et al., 1982; 1983). As fontes solúveis de $\mathrm{Zn}$, particularmente a mais comum, o sulfato, não são necessariamente as mais eficientes quando aplicadas via solo (Westfall et al., 1999). Por essa razão, os oxissulfatos, parcialmente solúveis em água, são produzidos e usados no Brasil.

Os métodos oficiais de análise de fertilizantes determinam que estes sejam moídos previamente e que a extração de $\mathrm{Zn}$ seja feita por $\mathrm{HCl}$ concentrado, a quente quando se tratar de materiais inorgânicos, com exceção das fritas (Brasil, 1988).

O objetivo deste trabalho foi avaliar o efeito de doses de $\mathrm{Zn}$, aplicado como oxissulfato de $\mathrm{Zn}$, nas formas granulada e em pó em duas cultivares de arroz.

\section{Material e Métodos}

O experimento foi realizado em casa de vegetação do Centro de Energia Nuclear na Agricultura da Universidade de São Paulo (Cena-USP), em Piracicaba, SP, entre dezembro de 2000 e junho de 2001.
Utilizou-se um Latossolo Vermelho distrófico, textura média, do Instituto de Zootecnia da Secretaria de Agricultura e Abastecimento de São Paulo, Município de Nova Odessa. Os resultados das análises químicas $(0-0,20 \mathrm{~m})$ foram os seguintes: $\mathrm{pH}\left(\mathrm{CaCl}_{2} 0,1 \mathrm{M}\right), 3,9 ; \mathrm{MO}, 23 \mathrm{~g} \mathrm{dm}^{-3}$; $\mathrm{P}$ (resina), $4 \mathrm{mg} \mathrm{dm}^{-3}$; $\mathrm{K}$ (resina), $0,9 \mathrm{mmol}_{\mathrm{c}} \mathrm{dm}^{-3}$; $\mathrm{Ca}$ (resina), $7 \mathrm{mmol}_{\mathrm{c}} \mathrm{dm}^{-3} ; \mathrm{Mg}$ (resina), $3 \mathrm{mmol}_{\mathrm{c}} \mathrm{dm}^{-3} ; \mathrm{S}^{-3} \mathrm{SO}_{4}$, $25 \mathrm{mg} \mathrm{dm}{ }^{-3} ; \mathrm{Al}, 8 \mathrm{mmol}_{\mathrm{c}} \mathrm{dm}^{-3} ; \mathrm{H}, 39 \mathrm{mmol}_{\mathrm{c}} \mathrm{dm}^{-3} ; \mathrm{SB}$, $10,9 \mathrm{mmol}_{\mathrm{c}} \mathrm{dm}^{-3}$; T, 57,9 $\mathrm{mmol}_{\mathrm{c}} \mathrm{dm}^{-3} ; \mathrm{V}, 19 \%$; $\mathrm{B}$ (água quente), $0,19 \mathrm{mg} \mathrm{dm}^{-3}$; $\mathrm{Fe}$ (DTPA), $104 \mathrm{mg} \mathrm{dm}^{-3}$; Mn (DTPA), 3,4 $\mathrm{mg} \mathrm{dm}^{-3}$; Zn (DTPA), 0,9 $\mathrm{mg} \mathrm{dm}^{-3}$. O solo seco foi misturado com $\mathrm{CaCO}_{3}$ e $\mathrm{MgCO}_{3}$ (p.a.), em partes iguais, para elevar a saturação por bases a $50 \%$, conforme Cantarella \& Furlani (1996). O período de incubação foi de 30 dias, durante o qual a umidade do solo foi mantida a $60 \%$ da capacidade de campo.

Vasos de barro providos de coletor e impermeabilizados internamente receberam $3 \mathrm{dm}^{3}$ de solo seco passado por peneira de $2 \mathrm{~mm}$.

Os vasos receberam $150 \mathrm{mg} \mathrm{dm}^{-3} \mathrm{de} \mathrm{N}$ fracionados em três vezes, cada um com $1 / 3$ da dose, na semeadura, misturada com o solo e com as demais fontes de nutrientes e duas coberturas, no início e no perfilhamento pleno; o N foi fornecido como nitrato de amônio na semeadura, e nas coberturas usou-se metade da dose como uréia e sulfato de amônio. O P foi aplicado na semeadura na forma de $\mathrm{Ca}\left(\mathrm{H}_{2} \mathrm{PO}_{4}\right)_{2}$.

A dose de $\mathrm{K}$ foi de $150 \mathrm{mg} \mathrm{dm}^{-3}$, um terço aplicado na semeadura como sulfato de potássio e dois terços fornecidos junto com o N, em partes iguais, na forma de cloreto de potássio. As doses de micronutrientes aplicadas apenas na semeadura $\mathrm{em} \mathrm{mg} \mathrm{dm}^{-3}$ foram as seguintes: $\mathrm{B}, 0,65$ $\left(\mathrm{H}_{3} \mathrm{BO}_{3}\right) ; \mathrm{Cu}, 1,0\left(\mathrm{CuCl}_{2} \cdot 2 \mathrm{H}_{2} \mathrm{O}\right) ; \mathrm{Mn}, 10\left(\mathrm{MnCl}_{2} \cdot 2 \mathrm{H}_{2} \mathrm{O}\right)$; Mo, $0,05\left(\mathrm{MoO}_{3}\right)$. Todos os produtos eram p.a. e foram aplicados em solução e misturados com o solo para depois compor os vasos.

A fonte de $\mathrm{Zn}$ utilizada foi um produto comercial originado do tratamento do óxido de Zn com ácido sulfúrico e subseqüente granulação, apresentando $24,9 \%$ de $\mathrm{Zn}$ total, sendo $69 \%$ solúvel em água. Este produto, oxissulfato de Zn, foi usado nas formas granulada e em pó, este obtido por moagem em almofariz de porcelana de modo a passar por peneira de $0,84 \mathrm{~mm}$ de malha (ABNT no 20). Foram utilizadas as doses $0,1,2,5 \mathrm{e} 10 \mathrm{mg} \mathrm{dm}^{-3}$ do produto, aplicado seco e misturado com o solo de cada vaso. Usou-se um tratamento padrão com $4 \mathrm{mg} \mathrm{dm}^{-3}$ de $\mathrm{Zn}$ na forma de sulfato de $\mathrm{Zn}$ heptaidratado.

As cultivares de arroz (Oriza sativa) utilizadas foram IAC 165 e IAC 202 e o delineamento experimental foi inteiramente casualizado, com quatro repetições.

Foram semeadas 10 sementes por vaso e, após o desbaste, foram deixadas apenas cinco plantas por vaso. 
As plantas foram irrigadas com água desionizada para compensar a evapotranspiração, procurando-se manter o solo com cerca de $60 \%$ do poder de embebição. No início do perfilhamento, colheu-se uma planta por vaso para a determinação de P e Zn na parte aérea (Malavolta et al., 1997). Quatro meses depois da germinação, as plantas foram colhidas separando-se raízes, colmos com folhas, ráquis e grãos, que, depois de secados a $70^{\circ} \mathrm{C}$, foram pesados, moídos e analisados quanto ao $\mathrm{P}$ e zinco. Após a colheita, coletou-se amostra de solo de cada vaso para a determinação de $\mathrm{P}$ e de Zn pelo extrator Mehlich 1 (Embrapa, 1997) e DTPA (Lindsay \& Norvell, 1978).

Os dados foram submetidos à análise de variância e as médias comparadas pelo teste de Tukey a 5\% de probabilidade. Análises de regressão foram usadas para estudar a relação entre as doses de $\mathrm{Zn}$ aplicadas no solo e o total desse nutriente absorvido por cultivar e a relação entre os teores de $\mathrm{Zn}$ das folhas e dos colmos de cada cultivar com os teores de Zn extraídos do solo pelas soluções de Mehlich 1 e DTPA.

\section{Resultados e Discussão}

No tratamento sem adição de $\mathrm{Zn}$, as duas cultivares apresentaram redução no crescimento e no perfilhamento, internódios mais curtos e manchas cor de ferrugem nas proximidades das margens das folhas mais novas, as quais lembram os sinais de brusone. Os sintomas observados concordam com a descrição de Barbosa Filho (1987), não sendo, porém, tão acentuados. $\mathrm{O}$ teor de $\mathrm{Zn}$ do solo original era de $0,9 \mathrm{mg} \mathrm{dm}^{-3}$ extraído pelo DTPA. É possível que a calagem e a adubação fosfatada tenham contribuído para reduzir a disponibilidade desse micronutriente ou, no caso da adubação fosfatada, a absorção e utilização do elemento, conforme Malavolta \& Gorostiaga (1974).

Somente o peso da ráquis não foi influenciado pela dose de Zn aplicada. Nas duas cultivares, o peso das raízes foi pouco influenciado pelos tratamentos de oxissulfato sob a forma de pó, ao contrário de quando usado sob a forma granulada, em que houve redução na produção de matéria seca, assim como verificado com a matéria seca dos colmos e folhas que diminuíram com doses mais altas (Figuras $1 \mathrm{e}$ 2). A produção de grãos respondeu de modo significativo às doses de $\mathrm{Zn}$, com comportamento semelhante ao do conjunto de colmos e folhas, o mesmo acontecendo com a matéria seca total produzida, exceção apenas na produção de grãos de IAC 165, que apresentou uma equação de primeiro grau.

Quanto à produção de grãos, a cultivar IAC 165 respondeu melhor à aplicação de oxissulfato sob a forma de pó, e IAC 202 à aplicação granulada (Figuras 1 e 2). Isto significa que esse produto usado na forma granulada, com as características de solubilidade que possui, é uma fonte eficiente de $\mathrm{Zn}$, dependendo da cultivar utilizada. A produção de grãos de IAC 165 obtida com $4 \mathrm{mg} \mathrm{dm}^{-3}$ de $\mathrm{Zn}$ (sulfato de $\mathrm{Zn}$ ) é próxima à mesma dose fornecida pelo oxissulfato em pó, porém maior com oxissulfato granulado (Figura 1). Já com IAC 202, houve resposta semelhante à curva de produção de grãos do granulado e maior com oxissulfato sob a forma de pó (Figura 2). Esses dados sugerem que a solubilidade total em água dos oxissulfatos não seja necessária, sendo suficientes de acordo com Westfall et al. (1999), apenas 50\%.

Quanto aos teores de $\mathrm{P}$ e $\mathrm{Zn}$ nas folhas e nos colmos, por ocasião do perfilhamento, a relação $\mathrm{P} / \mathrm{Zn}$ foi influenciada pelos tratamentos (Figuras $3 \mathrm{e}$ 4). A produção máxima de grãos de IAC 165 ocorreu com 4,82 $\mathrm{mg} \mathrm{dm}^{-3}$ de $\mathrm{Zn}$ sob a forma de oxissulfato em pó, e em IAC 202, na presença de 5,32 e $5,82 \mathrm{mg} \mathrm{dm}^{-3}$ de $\mathrm{Zn}$, respectivamente, sob as formas de pó e granulada (Figuras 1 e 2). Tais produções correspondem aos teores, no caso de IAC 165, de $132 \mathrm{mg} \mathrm{dm}^{-3} \mathrm{de} \mathrm{Zn}$ nas folhas e colmos (Figura 3). Em IAC 202, os teores para produção máxima são de 62 e $53 \mathrm{mg} \mathrm{kg}^{-1}$ de $\mathrm{Zn}$ nas folhas e 135 e $92 \mathrm{mg} \mathrm{kg}^{-1}$ de Zn nos colmos, respectivamente, com oxissulfato em pó e granulado (Figura 4). Essas produções foram obtidas com $101 \mathrm{e}$ $45 \mathrm{mg} \mathrm{kg}^{-1}$ de $\mathrm{Zn}$ nas folhas e de 108 e $92 \mathrm{mg} \mathrm{kg}^{-1}$ de $\mathrm{Zn}$ nos colmos nas cultivares IAC 165 e IAC 202, respectivamente. Nas duas cultivares, aparentemente a relação $\mathrm{P} / \mathrm{Zn}$ na folha reflete melhor o estado nutricional e a influência dos tratamentos. Os teores de $\mathrm{Zn}$ encontrados são muito diferentes dos relatados na literatura, possivelmente pela diferença no órgão e época de amostragem (folha Y ou folha bandeira). Reuter et al. (1997) apresentaram resultados das determinações feitas no perfilhamento usando toda a parte aérea, isto é, colmos e folhas juntos, de plantas cultivadas em solo. Esses autores constataram que os teores de $\mathrm{P}$ estavam entre 3,7 e $5,5 \mathrm{~g} \mathrm{~kg}^{-1}$, 

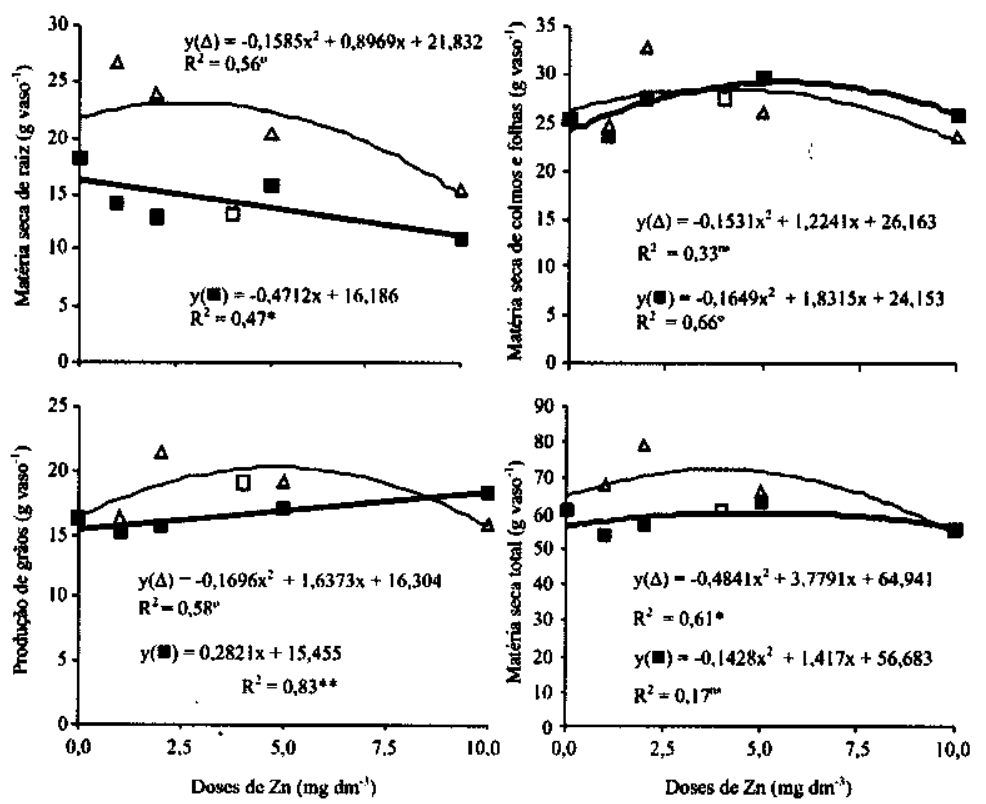

Figura 1. Produção de grãos e de matéria seca de raiz, de colmo e folhas e total pela cultivar de arroz IAC 165 em resposta a doses de $\mathrm{Zn}$, aplicadas no solo como oxissulfato em pó ( $\triangle$ ) e granulado ( $\square$ ) e sob a forma de sulfato de $\mathrm{Zn}$ ((口) usado como fonte padrão. "Não-significativo. ${ }^{\circ},{ }^{*} \mathrm{e}^{* *}$ Significativo a $10 \%$, a $5 \%$ e a $1 \%$ de probabilidade, respectivamente.
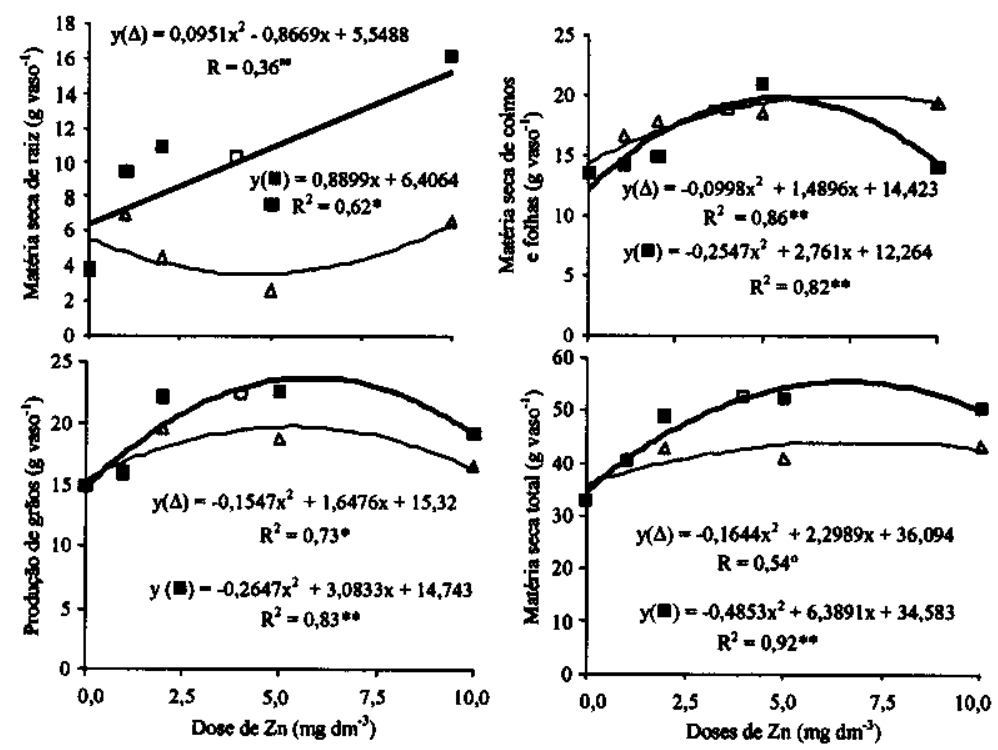

Figura 2. Produção de grãos e de matéria seca de raiz, de colmo e folhas e total pela cultivar de arroz IAC 202 em resposta a doses de $Z n$, aplicadas no solo como oxissulfato em pó ( $\triangle$ ) e granulado ( $($ ) e sob a forma de sulfato de $\mathrm{Zn}$ (ㅁ) usado como fonte padrảo. ${ }^{\text {m}}$ Não-significativo. ${ }^{\circ},{ }^{*} \mathrm{e}$ * Significativo a $10 \%$, a $5 \%$ e a $1 \%$ de probabilidade, respectivamente. 
acima dos encontrados no presente trabalho em que as duas partes foram analisadas separadamente. No trabalho de Reuter et al. (1997), os níveis de Zn são classificados como deficientes: 75 a $85 \mathrm{mg} \mathrm{kg}^{-1}$; adequados: 86 a $375 \mathrm{mg} \mathrm{kg}^{-1}$; críticos $375 \mathrm{mg} \mathrm{kg}^{-1}$; e tóxicos: $500 \mathrm{mg} \mathrm{kg}^{-1}$. Os teores encontrados no presente trabalho mostram efeito varietal, ou seja, o nível correspondente a IAC 165 estaria na faixa adequada, mas o de IAC 202 seria considerado deficiente.
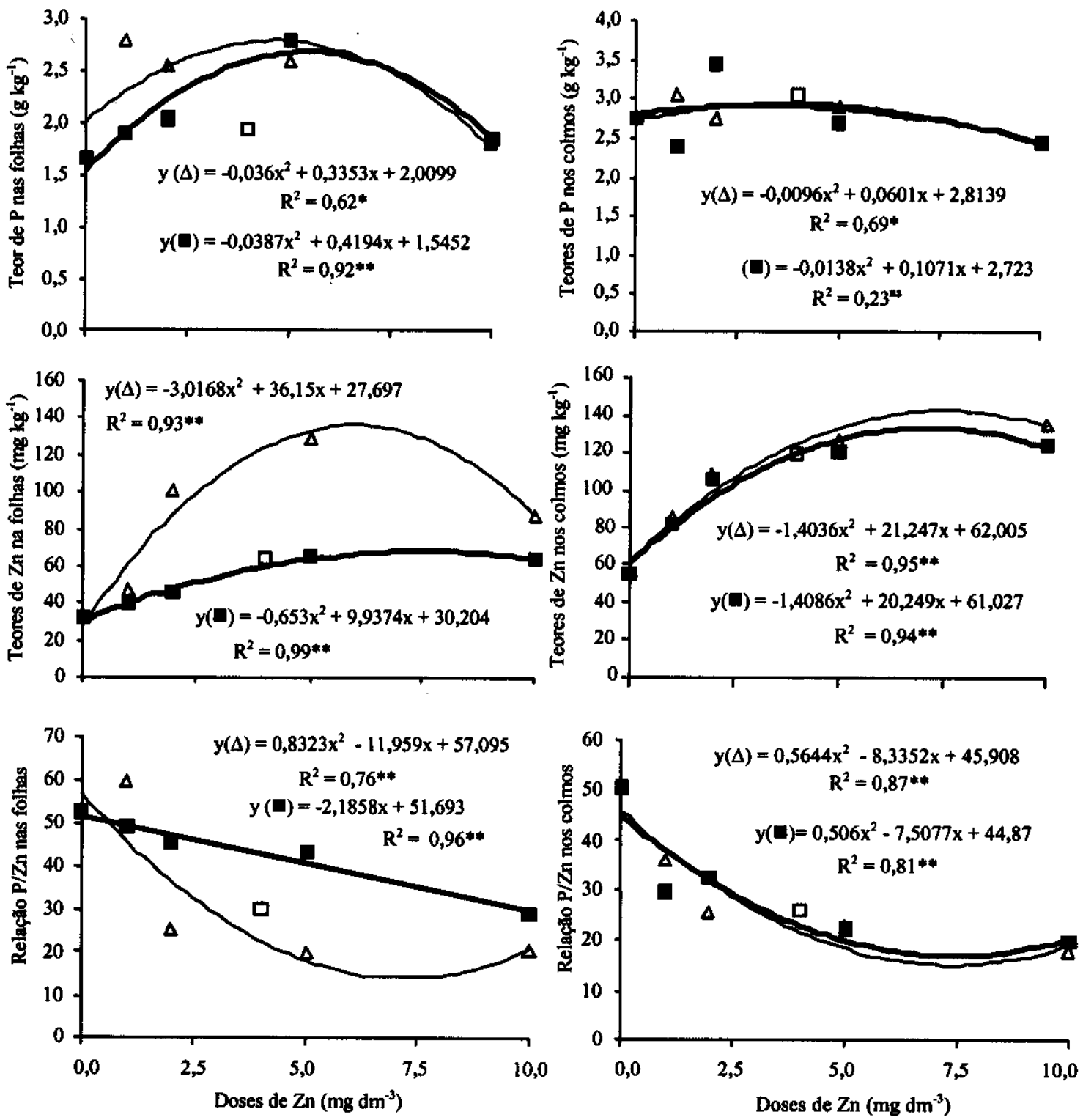

Figura 3. Teores de $\mathrm{P}\left(\mathrm{g} \mathrm{kg}^{-1}\right)$ e $\mathrm{Zn}$ (mg kg-1) no perfilhamento pela cultivar de arroz IAC 165 em razão da aplicação de oxissulfato de $\mathrm{Zn}$ em pó ( $\triangle$ ) e granulado (a) e sob a forma de sulfato de $\mathrm{Zn}$ (ם) usado como fonte padrão.

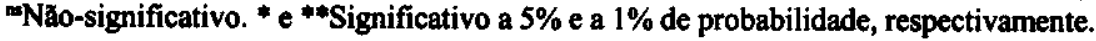


$\mathrm{Na}$ relação entre as doses de $\mathrm{Zn}$ aplicadas e o conteúdo do elemento, os valores de $\mathbf{R}^{2}$ foram significativos (Figura 5). De modo geral, a resposta medida pela absorçăo do Zn foi semelhante à da produção de grãos.
A eficiência de utilização do $\mathrm{Zn}$ (EUZn) é obtida pela divisão da produção máxima de grãos (g) pela quantidade total do elemento absorvido (mg) (Malavolta \& Amaral, 1978):
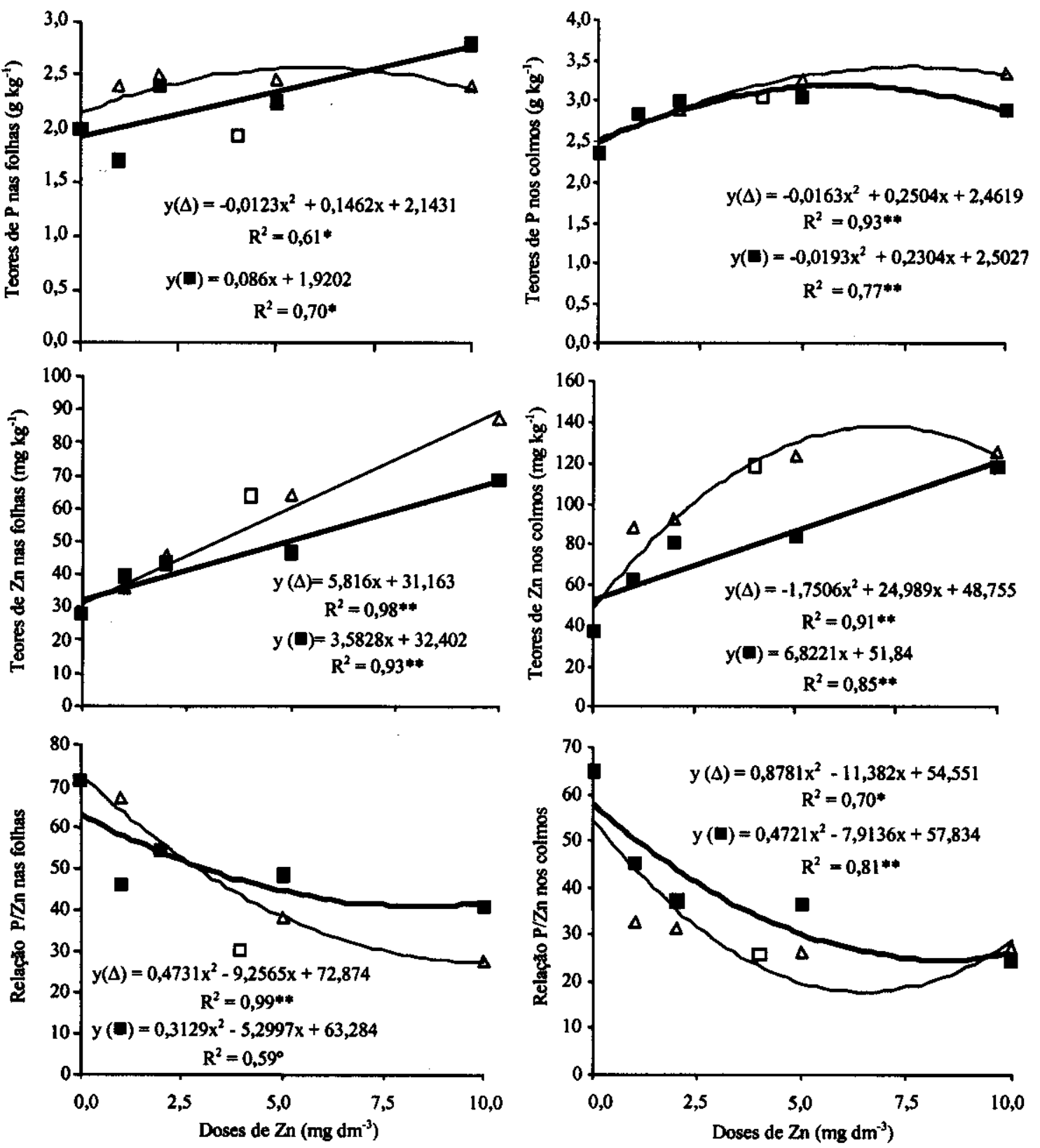

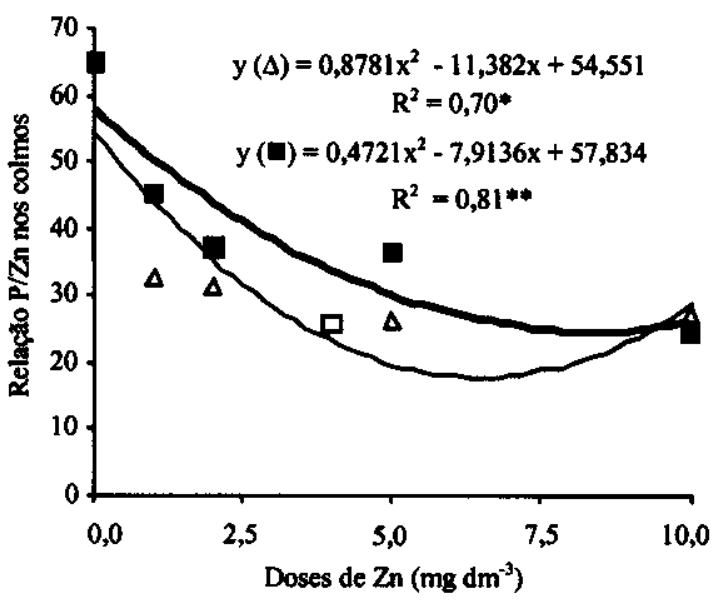

Figura 4. Teores de $\mathrm{P}\left(\mathrm{g} \mathrm{kg}^{-1}\right) \mathrm{e} \mathrm{Zn}$ (mg kg-1) no perfilhamento pela cultivar de arroz IAC $202 \mathrm{em} \mathrm{razão} \mathrm{da} \mathrm{aplicação} \mathrm{de}$ oxissulfato de $\mathrm{Zn}$ em pó ( $\Delta$ ) e granulado (G) e da aplicação de sulfato de $\mathrm{Zn}$ ( $\square$ ) usado como fonte padrăo. $:{ }^{*}$ e **Significativo a $10 \%$, a $5 \%$ e a $1 \%$ de probabilidade, respectivamente. 
EUZn IAC $165=22,5 / 5,93=3,79 \mathrm{~g} \mathrm{mg}^{-1}$; EUZn IAC 202 $=20,7 / 3,10=6,67 \mathrm{~g} \mathrm{mg}^{-1}$.

Portanto, IAC 202 é mais eficiente na utilização do $\mathrm{Zn}$ na formação de colheita do que IAC 165. Trabalhando com dez genótipos de arroz irrigado com adição de 0 e $10 \mathrm{mg} \mathrm{kg}^{-1}$ de $\mathrm{Zn}$ no solo, Fageria (2001) não obteve resposta ao $\mathrm{Zn}$ em relação à produção de grâos em vasos cujo teor desse nutriente no solo era de $1,2 \mathrm{mg} \mathrm{dm}^{-3}$ (Mehlich 1). Esse mesmo autor calculou a eficiência de utilização do $\mathrm{Zn}$, sem recorrer à análise das plantas, com auxílio da fórmula: índice de eficiência para colheita de grãos = (rendimento de grãos no nível baixo de $\mathrm{Zn} /$ média de rendimento experimental com alto nível de $\mathrm{Zn}$ ) e verificou por esse procedimento que havia diferença genotípica.

Em IAC 165, os teores de $\mathrm{Zn}$ extraídos do solo aumentaram consistentemente com a dose aplicada; em IAC 202 ocorreu uma inexplicável diminuição com a dose mais alta de $\mathrm{Zn}$, independentemente da granulometria (Tabela 1).

Os dois extratores em geral se comportaram de modo semelhante na sua relação com os teores de
Zn no tecido (Tabela 2). Ambos guardaram relação linear de igual significância com as doses aplicadas. Fazendo-se $\mathrm{x}=$ dose de $\mathrm{Zn} \mathrm{em} \mathrm{mg} \mathrm{dm} \mathrm{dm}^{-3}$ e $\mathrm{y}=$ teor no solo em mg dm$~^{-3}$, as equaç̋̃es são as seguintes para as duas cultivares em conjunto:

$y=1,58+0,203 x, \quad R^{2}=0,83 * *$ (Mehlich 1, oxissulfato aplicado na forma de pó);

$y=0,69+0,094 x, R^{2}=0,81^{* *} \quad$ (DTPA);

$y=1,13+0,342 x, R^{2}=0,63^{* *} \quad($ Mehlich 1, oxissulfato aplicado na forma granulada);

$y=0,57+0,095 x, R^{2}=0,78^{* *} \quad$ (DTPA).

Esses valores sugerem que os dois extratores forneceram a mesma informação na avaliação do nível de $\mathrm{Zn}$ disponível no solo. De fato, foram encontrados os seguintes coeficientes de correlação linear (r) entre os valores obtidos:

Mehlich 1, produto em pó x DTPA, $r=0,89 * *$; Mehlich 1, produto granulado $x$ DTPA, $r=0,80^{* *}$; Mehlich 1, ambos produtos $x$ DTPA, $r=0,78 * *$. Galrão (1988) também constatou correlação semelhante entre os dois extratores em trabalho realizado no campo com milho. O extrator de Mehlich 1 além de extrair $\mathrm{Zn}$ extrai também $\mathrm{P}, \mathrm{K}, \mathrm{Ca}, \mathrm{Mg}, \mathrm{Cu}, \mathrm{Fe}$ e $\mathrm{Mn}$
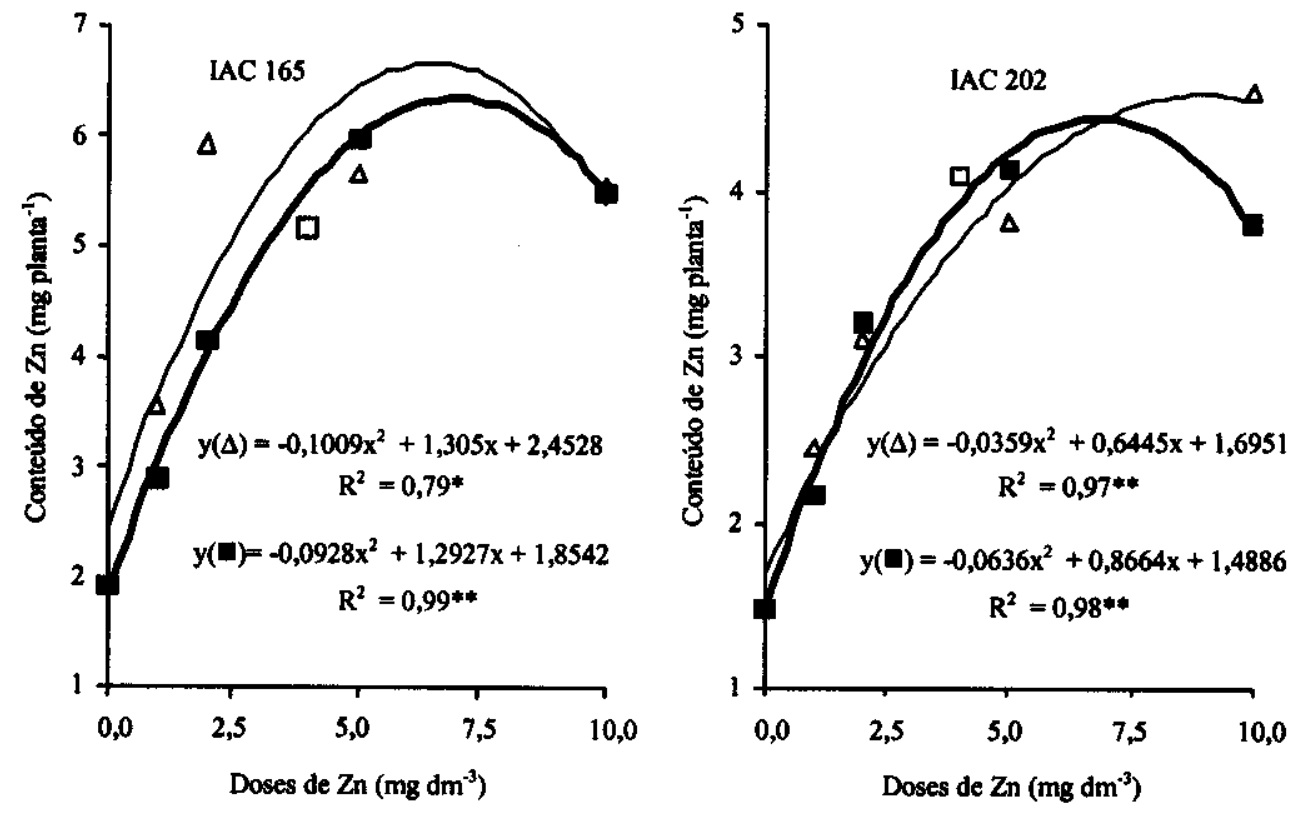

Figura 5. Conteúdo de $\mathrm{Zn}$ por planta, em razão das doses de $\mathrm{Zn}$ aplicadas sob a forma de oxissulfato, em pó $(\Delta)$ e granulado $(\square)$, e sob a forma de sulfato de $\mathrm{Zn}$ ( $\square$ ) usado como fonte padrăo em duas cultivares de arroz. ${ }^{*} e^{* *}$ Significativo a $5 \%$ e a $1 \%$ de probabilidade, respectivamente. 
Tabela 1. Teores de $\mathrm{Zn}$ extraído do solo $\left(\mathrm{mg} \mathrm{dm}^{-3}\right)$ pelas soluções de Mehlich 1 e DTPA após a colheita das cultivares de arroz IAC 165 e IAC 202 em razão das doses de oxissulfato de Zn, em pó e granulado, aplicadas no solo(1).

\begin{tabular}{|c|c|c|c|c|}
\hline \multirow{2}{*}{$\begin{array}{l}\text { Doses de oxissulfato } \\
\text { de } \mathrm{Zn}^{(2)}\left(\mathrm{mg} \mathrm{dm}^{-3}\right)\end{array}$} & \multicolumn{2}{|c|}{ IAC 165} & \multicolumn{2}{|c|}{ IAC 202} \\
\hline & Mehlich 1 & DTPA & Mehlich 1 & DTPA \\
\hline \multirow[t]{2}{*}{0} & $0,91 \mathrm{e}$ & $0,42 \mathrm{e}$ & $2,0 \mathrm{~b}$ & $0,88 \mathrm{~cd}$ \\
\hline & \multicolumn{4}{|c|}{ Pó } \\
\hline 1 & $1,76 \mathrm{bcd}$ & $1,02 \mathrm{bcd}$ & $2,2 b$ & $0,86 \mathrm{~cd}$ \\
\hline 2 & $2,24 b c$ & $1,08 \mathrm{bcd}$ & $2,3 b$ & $1,14 a b c$ \\
\hline 5 & $2,92 \mathrm{ab}$ & $1,16 a b c d$ & $3,3 \mathrm{ab}$ & $1,61 \mathrm{a}$ \\
\hline \multirow[t]{2}{*}{10} & $3,71 \mathrm{a}$ & $1,59 \mathrm{a}$ & $1,2 \mathrm{~b}$ & $0,49 \mathrm{~d}$ \\
\hline & \multicolumn{4}{|c|}{ Granulado } \\
\hline 1 & $1,40 \mathrm{~cd}$ & $0,70 \mathrm{de}$ & $2,6 b$ & $1,03 \mathrm{bcd}$ \\
\hline 2 & $1,85 \mathrm{bcd}$ & $0,89 \mathrm{cde}$ & $2,5 b$ & $1,27 \mathrm{abc}$ \\
\hline 5 & $2,10 \mathrm{bcd}$ & $0,81 \mathrm{de}$ & $6,1 \mathrm{a}$ & $1,53 \mathrm{ab}$ \\
\hline 10 & $3,50 \mathrm{a}$ & $1,43 \mathrm{ab}$ & $3,4 \mathrm{ab}$ & $1,27 \mathrm{abc}$ \\
\hline $\mathrm{ZnSO}_{4} \cdot 7 \mathrm{H}_{2} \mathrm{O}\left(4 \mathrm{mg} \mathrm{dm}^{-3}\right)$ & $3,60 \mathrm{a}$ & $1,33 a b c$ & $1,7 \mathrm{~b}$ & $0,51 \mathrm{~d}$ \\
\hline
\end{tabular}

Tabela 2. Relação entre os teores de $\mathrm{Zn}$ dos colmos e das folhas de duas cultivares de arroz e os teores de $\mathrm{Zn}$ extraídos do solo pelas soluções de Mehlich 1 e DTPA, em razão da aplicação de oxissulfato de Zn, em pó e granulado.

\begin{tabular}{|c|c|c|c|}
\hline Cultivar & Órgão & Equação & $\mathrm{R}^{2}$ \\
\hline \multirow{5}{*}{ IAC 165} & & Pó & \\
\hline & Folha & $Y=-18,227 x^{2}+111,31 x-64,931($ Mehlich 1) & $0,76^{*}$ \\
\hline & & $Y=58,956 x+16,061(D T P A)$ & $0,41^{\mathrm{ns}}$ \\
\hline & Colmo & $Y=-6,857 x^{2}+61,535 x+2,9003($ Mehlich 1$)$ & $0,87 *$ \\
\hline & & $Y=-13,549 x^{2}+99,496 x+14,268(D T P A)$ & $0,99 * *$ \\
\hline \multirow[t]{4}{*}{ IAC 202} & Folha & $Y=5,2001 x^{2}-2,6007 x+25,527($ Mehlich 1$)$ & $0,99 * *$ \\
\hline & & $Y=42,957 x^{2}-33,44 x+33,645($ DTPA $)$ & $0,90 *$ \\
\hline & Colmo & $Y=-11,205 x^{2}+83,544 x-29,74$ (Mehlich 1$)$ & $0,91 *$ \\
\hline & & $Y=-39,949 x^{2}+158,72 x-24,149$ (DTPA) & $0,97 *$ \\
\hline \multirow{5}{*}{ IAC 165} & & Granulado & \\
\hline & Folha & $Y=-7,1322 x^{2}+45,241 x-6,385$ (Mehlich 1) & $0,84^{*}$ \\
\hline & & $Y=-73,119 x^{2}+202,16 x-43,46($ DTPA $)$ & $0,52 *$ \\
\hline & Colmo & $Y=-19,295 x^{2}+112,63 x-33,644$ (Mehlich 1) & $0,88^{*}$ \\
\hline & & $\mathrm{Y}=-98,251 \mathrm{x}^{2}+252,38 \mathrm{x}-35,553(\mathrm{DTPA})$ & $0,99 * *$ \\
\hline \multirow[t]{4}{*}{ IAC 202} & Folha & $Y=-0,4149 x^{2}+17,11 x+14,064$ (Mehlich 1) & $0,98^{* *}$ \\
\hline & & $\mathrm{Y}=2,0892 \mathrm{x}^{2}+35,941 \mathrm{x}+12,931(\mathrm{DTPA})$ & $0,98^{* *}$ \\
\hline & Colmo & $Y=-8,5107 x^{2}+68,172 x-17,142($ Mehlich 1$)$ & $0,99 * *$ \\
\hline & & $Y=-40,282 x^{2}+155,03 x-21,991(D T P A)$ & $0,98 * *$ \\
\hline
\end{tabular}

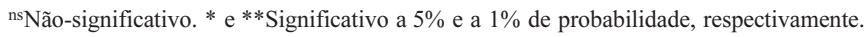


no mesmo extrato, o que permite a determinação de todos esses nutrientes em apenas uma extração.

\section{Conclusões}

1. As cultivares de arroz IAC 165 e IAC 202 respondem à adição de $\mathrm{Zn}$ na forma de oxissulfato parcialmente solúvel em água.

2. O oxissulfato em pó na cultivar IAC 165 e granulado na cultivar IAC 202 apresentam produção de grãos semelhante à obtida com o sulfato de $\mathrm{Zn}$ (fonte padrão).

3. As cultivares IAC 165 e IAC 202 diferem quanto à eficiência de utilização do $\mathrm{Zn}$ na formação da colheita, ou seja, de utilização de nutriente e demais fatores da planta e do meio para vegetação e produção de grãos.

4. Os teores de Zn no solo extraídos pelas soluções de Mehlich 1 e DTPA se correlacionam significativamente com as doses de $\mathrm{Zn}$ aplicadas e com os teores desse nutriente da parte aérea.

\section{Agradecimentos}

Ao Dr. Valdinei T. Paulino, do Instituto de Zootecnia da Secretaria de Abastecimento de São Paulo, e ao Dr. Akihiko Ando, da Esalq e do Cena (USP), pelo fornecimento do solo e das sementes das cultivares de arroz, respectivamente.

\section{Referências}

ASSOCIAÇÃO NACIONAL PARA DIFUSÃO DE ADUBOS (São Paulo, SP). Anuário estatístico setor de fertilizantes: 2000. São Paulo, 2001. 152 p.

BARBOSA FILHO, M. P. Nutrição e adubação do arroz (sequeiro e irrigado). Piracicaba: Potafos, 1987. 120 p. (Boletim Técnico, 9).

BARBOSA FILHO, M. P.; FAGERIA, N. K.; CARVALHO, J. R. P. Fontes de zinco e modo de aplicação sobre a produção de arroz em solos de cerrado. Pesquisa Agropecuária Brasileira, Brasília, v. 17, n. 12, p. 17131719, dez. 1982.

BARBOSA FILHO, M. P.; FAGERIA, N. K.; FONSECA, J. R. Tratamento de sementes de arroz com micronutrientes sobre o rendimento e qualidade de grãos. Pesquisa Agropecuária Brasileira, Brasília, v. 18, n. 3, p. 219-222, mar. 1983.

BRASIL. Ministério da Agricultura. Secretaria Nacional de Defesa Agropecuária. Laboratório Nacional de Refe- rência Vegetal. Análise de corretivos, fertilizantes e inoculantes: métodos oficiais. Brasília, 1988. 104 p.

BROWN, J. C.; AMBLER, J. E.; CHANEY, R. L.; FOY, C. D. Differential responses of plant genotypes to micronutrients. In: MORTVEDT, J. J.; GIORDANO, P. M.; LINDSAY, W. L. (Ed.). Micronutrientes in agriculture. Madison: Soil Science Society of America, 1972. p. 389-418.

CANTARELLA, H.; FURLANI, P. R. Arroz de sequeiro. In: RAIJ, B. van; CANTARELLA, H.; QUAGGIO, J. A.; FURLANI, A. M. C. (Ed.). Recomendações de adubação e calagem para o Estado de São Paulo. Campinas: Instituto Agronômico, 1996. p. 46-49. (Boletim, 100).

EMBRAPA. Centro Nacional de Pesquisa de Solos (Rio de Janeiro, RJ). Manual de métodos de análise de solo. 2. ed. Rio de Janeiro: Embrapa-CNPS, 1997. 212 p.

FAGERIA, N. K. Screening method of lowland rice genotypes for zinc uptake efficiency. Scientia Agricola, Piracicaba, v. 58, p. 623-626, 2001.

GALRÃO, E. Z. Respostas das culturas aos micronutrientes boro e zinco. In: SIMPÓSIO SOBRE ENXOFRE E MICRONUTRIENTES NA AGRICULTURA BRASILEIRA, 1988, Londrina. Anais... Londrina: Embrapa-CNPSo/IAPAR/Sociedade Brasileira de Ciência do Solo, 1988. p. 205-237.

LINDSAY, W. L.; NORVELL, W. A. Development of DTPA soil test for zinc, iron, manganese and copper. Soil Science Society of America Journal, Madison, v. 42, p. 421-428, 1978.

LOPES, A. S. Micronutrientes, filosofias de aplicação e eficiência agronômica. São Paulo: Associação Nacional para Difusão de Adubos, 1999. 70 p. (Boletim Técnico, $8)$.

LUCAS, R. E.; KNEZEK, B. D. Climatic and soil conditions promoting micronutrient deficiencies in plants. In: MORTVEDT, J. J.; GIORDANO, P. M.; LINDSAY, W. L. (Ed.). Micronutrients in agriculture. Madison: Soil Science Society of America, 1972. p. 265-288.

MALAVOLTA, E.; AMARAL, F. A. L. Nutritional efficiency of 104 bean varieties (Phaseolus vulgaris L.). In: INTERNATIONAL COLLOQUIUM ON PLANT ANALYSIS AND FERTILIZER PROBLEMS, 8., 1978, Auckland. Proceedings... Auckland: New Zealand Department of Scientific \& Industrial Research, 1978. v. 2, p. 313-317. 
MALAVOLTA, E.; GOROSTIAGA, O. L. Studies on the zinc phosphate relationships in plants. In: INTERNATIONAL COLLOQUIUM ON PLANT ANALYSIS AND FERTILIZER PROBLEMS, 7., 1974, Hanover. Proceedings... Hanover: German Society of plant Nutrition, 1974. v. 2, p. 261-272.

MALAVOLTA, E.; BOARETTO, A. E.; PAULINO, V. T. Micronutrientes: uma visão geral. In: FERREIRA, M. E.; CRUZ, M. C. P. (Ed.). Micronutrientes na agricultura. Piracicaba: Potafos/CNPq, 1991. p. 1-34.

MALAVOLTA, E.; VITTI, G. C.; OLIVEIRA, S. A. Avaliação do estado nutricional das plantas: princípios e aplicações. 2. ed. Piracicaba: Potafos, 1997. 319 p.
REUTER, D. J.; EDWARDS, D. G.; WILHELM, N. S. Temperate and tropical crops. In: REUTER, D. J.; ROBINSON, J. B. (Ed.). Plant analysis an interpretation manual. Collingwood: Commonwealth Scientific and Industrial Research Organization, 1997. p. 1984-1992.

RIBEIRO, A. C.; GUIMARÃES, P. T. G.; ALVAREZ VENEGAS, V. H. (Ed.). Recomendações para o uso de corretivos e fertilizantes em Minas Gerais: 5th aproximação. Viçosa, MG: Comissão de Fertilidade do Solo do Estado de Minas Gerais, 1999. 359 p.

WESTFALL, D. G.; AMARANI, M.; PETERSON, G. A. Water solubility of zinc fertilizer: does it matter? Better Crops, Saskatoon, v. 83, n. 2, p. 18-21, 1999. 